\title{
EFEKTIVITAS PENGEMBANGAN KARIR TERHADAP PRODUKTIVITAS KERJA KARYAWAN DI PT. SENAMAS ENERGINDO MINERAL
}

\author{
Riska Pebriyanti ${ }^{1}$, Faizal Mulia ${ }^{2}$, R. Deni Muhammad Danial ${ }^{3}$ \\ ${ }^{123}$ Fakultas Ilmu Administrasi Bisnis dan Humaniora, Universitas Muhammadiyah Sukabumi \\ ${ }^{1}$ Riskapebriyanti@ummi.ac.id, ${ }^{2}$ faizal_88@ummi.ac.id, ${ }^{3}$ rdmdanial043@ummi.ic.ad
}

\section{Artikel History:}

Artikel masuk

Artikel revisi

Artikel diterima

Kata Kunci:

Pengembangan Karir, Produktivitas Kerja

Keywords:

Career Development, Work Productivity

\begin{abstract}
ABSTRAK
Tujuan dari penelitian ini adalah untuk mengetahui dan menganalisis efektivitas pengembangan karir terhadap produktivitas kerja karyawan di PT. Senamas Energindo Mineral Jakarta. Metode yang digunakan adalah metode kuantitatif. Populasi dalam penelitian ini adalah karyawan tetap PT. Senamas Energindo Mineral. Serta teknik pengambilan sampel menggunakan teknik random sampling dengan jumlah responden 74 orang. Sumber data diperoleh dari kuesioner yang dibagikan kepada karyawan di PT. Senamas Energindo Mineral. Kemudian data yang diperoleh dianalisis menggunakan analisis regresi linier sederhana, analisis ini meliputi uji instrumen, uji t, dan uji F. Dari hasil pengolahan data penelitian ini menunjukan bahwa $t$ hitung sebesar $2.251>\mathrm{t}$ tabel 1.996, serta nilai signifikannya sebesar $0.000<0.05$ sehingga dapat disimpulkan bahwa variabel pengembangan karir berpengaruh terhadap variabel produktivitas kerja. Sedangkan uji F sebesar F hitung $5.067>3.97$, serta nilai signifikan sebesar $0.000<0.05$ sehingga dapat disimpulkan terdapat pengaruh secara signifikan positif antara variabel pengembangan karir terhadap variabel produktivitas kerja.
\end{abstract}

\section{ABSTRACT}

The purpose of this research is to study and analyze career development towards increasing employee productivity at PT. Senamas Energindo Mineral Jakarta. The method used is a quantitative method. The population in this study is a permanent company PT. Senamas Energindo Mineral. And the sampling technique uses ramdom sampling technique with 74 respondents. Sources of data obtained from questionnaires distributed to employees at PT. Senamas Energindo Mineral. Then the data obtained were analyzed using simple linier regression analysis, this analysis completes the instrument test, $t$ test, and $F$ test.from the results of this research data processing showed $t$ count of $2.251>t$ table 1.996, and a significance value of $0.000<0.05$ so can assessment career development variable. While the $F$ test of $F$ count is $5.067>3.97$, and a significant value of $0.000<0.05$ so it can be councluded that there is a significant positive affect between career development variables on work productivity variabel. 


\section{PENDAHULUAN}

Dijaman sekarang organisasi-organisasi mulai menjadikan SDM sebagai sumber daya utama dari suatu perusahaan sehingga mulai terbentuk adanya departemen Sumber Daya Manusia. Sumber daya manusia itu menjadi penting karena menjadi faktor penggerak suatu perusahaan, maka dari itu peningkatan pribadi seseorang dalam suatu perusahaan harus diutamakan dalam mencapai suatu rencana kerja yang efektif dengan cara mengembangkan karir karyawannya. Pengembangan karir karyawan perlu dilakukan secara terencana dengan baik agar mewujudkan manusia yang berbudi luhur, cerdas, terampil, mandiri dan produktif. Program pengembangan karir sangat penting dilakukan karena demi menyesuaikan kebutuhan dan tujuan karyawan dengan kesempatan karir yang tersedia diperusahaan. Pengembangan karir karyawan bertujuan untuk meningkatkan kemampuan teknis, teoritis, konseptual dan moral pegawai, agar produktivitas baik dan mencapai hasil yang optimal.

Setiap perusahaan atau organisasi pasti berupaya untuk menciptakan produktivitas yang tinggi. Produktivitas merupakan salah satu bagian terpenting yang mendapat perhatian perusahaan karena produktivitas adalah salah-satu indikator keberhasilan perusahaan.

Erat kaitannya dengan masalah produktivitas adalah pengembangan karir karyawan. Menurut Veithzal Rivai (dalam Abdullah, 2016) mengemukakan bahwa pengembangan karir adalah proses peningkatan kemampuan kerja individu yang dicapai dalam rangka mencapai karir yang diinginkan. Dimana pengembangan karir merupakan pendekatan formal perusahaan. Oleh karena itu perusahaan perlu mengelola karir dan mengembangkannya dengan baik agar produktivitas karyawan tetap terjaga dan mampu mendorong karyawan untuk selalu bekerja dengan efektiv.

PT. Senamas Energindo Mineral adalah perusahaan yang bergerak di bidang pertambangan yang merupakan bagian dari Rimau Group. PT. SEM didirikan oleh bapak Andrew Wang/Wang Chia Ing pada tahun 2008 yang bertempat di Jl. A. M. Sangaji Raya No 11, Kelurahan Petojo Utara, Jakarta Pusat, Rt 09/ Rw 07. PT SEM juga memiliki anak cabang yang berada di Tamiyang Layang, Barito Timur, Kalimantan Tengah. PT. SEM memiliki asset pertambangan yang tinggi menumbuhkan kapasitas dan memperluas pasaran Senamas Energindo Mineral di Indonesia. PT. Senamas Energindo Mineral selalu berusaha meningkatkan kemampuan sumber daya manusianya. Untuk itu segala keperluan yang mendukung kelancaran pekerjaan karyawan dan lingkungan kerja harus terus ditingkatkan agar mendukung tercapainya produktivitas kerja yang tinggi. 
R Pebriyanti, F Mulia, R D M Danial/ Jimek vol 3 No 1 Tahun 2020

Pengembangan karir yang dilakukan pada perusahaan adalah suatu upaya untuk meningkatkan dan mengembangkan status karyawan yang berada di perusahaan atau organisasi, dengan adanya pengembangan karir yang baik di suatu perusahaan dapat memotivasi karyawan bekerja secara maksimal. Hal itu juga dapat berpengaruh terhadap produktivitas kerja karyawan yang meningkat. Selain karyawan merasa puas akan karirnya, juga dapat memajukan perusahaan tersebut. Berdasarkan observasi yang dilakukan peneliti menemukan penomena yang sering terjadi di PT. Senamas Energindo Mineral adalah adanya karyawan yang sudah bekerja dan mengamdi pada perusahaan lebih lama tapi belum diangkat juga jabatannya serta kemampuan karyawan dalam menyelesaikan pekerjaan masih sangatlah kurang mengakibatkan produktivitas menurun.

Berdasarkan fenomena-fenomena tersebut, maka penulis mencoba untuk melakukan penelitian pada pengembangan karir karyawan di PT. Senamas Energindo Mineral untuk dapat meningkatkan produktivitas kerja karyawannya.

\section{TINJAUAN PUSTAKA}

\section{Pengembangan Karir}

Menurut Hani T. Handoko (dalam Supendy \& Harsum, 2018) mengemukakan istilah karir digunakan untuk menunjukan orang-orang pada masing-masing peranan atau status mereka.

Sedangkan menurut Rivai (dalam Juwita, 2016) karier terdiri dari semua pekerjaan yang ada selama seseorang bekerja atau dapat pula dikatakan karir adalah seluruh jabatan yang didudukin oleh seseorang dalam kehidupan kerjanya.

Pengembangan karir atau career development menurut Sudiro (dalam Massie, Tewal, \& Sendow, 2015) yaitu proses peningkatan kemampuan kerja karyawan dalam rangka mencapai karir yang diinginkan, peningkatan kemampuan ini bisa dari pelatihan yang dilakukan oleh karyawan.

Adapun dimensi pengembangan karier menurut menurut beberapa pada ahli meliputi:

\section{Education}

Handoko (dalam Fauzi \& Siregar, 2015) Pendidikan adalah faktor penentu sikap seseorang yang memiliki hubungan yang erat dengan apa yang seseorang pikirkan dan lakukan. Semakin baik pendidikan maka semakin baik pengetahuan dalam melakukan pekerjaan 


\section{Training programs}

Menurut Karter (dalam Litano \& Major, 2016) "employee career development was supported by training programs"

Pelatihan merupakan proses mengajarkan pengetahuan dan keahlian tertentu serta sikap agar pegawai semakin terampil dan mampu melaksanakan tanggung jawab dengan semakin baik

\section{Experience}

Baruch dan Rosenstein (dalam Litano \& Major, 2016) mendefinikan karier sebagai " $a$ process of development of the employee through a path of experience and jobs in the organization".

Pengalaman kerja adalah tingkat penguasaan pengetahuan serta keterampilan seseorang yang dapat diukur dari masa kerja seseorang.

\section{Tujuan Pengembangan Karir}

Menurut malayu (dalam Juwita, 2016), tujuan pengembangan karir adalah:

\section{Produktivitas Kerja}

Hasil kerja seseorang yang bisa dinikmati sesuai dengan kualitas dan pengembangan karier seseorang.

2. Efisiensi

Keefktivitasan pegawai dalam menjalankan tugas demi meraih produktivitas.

3. Kerusakan

Kerusakan kepercayaan atasan terhadap bawahan itu hal wajar, begitu juga para bawahan harus menjaga agar nama baiknya tidak rusak.

4. Kecelakaan

Kecelakan dalam pekerjaan itu tanggung jawab bersama.

5. Pelayanan

Pelayanan dalam dunia kerja sangatlah penting sesuai dengan kaidah kerja.

6. Moral

Moral bawahan ataupun pegawai harus di jaga dalam dunia kerja

7. Karir

Setiap pegawai bisa mengembangkan karirnya sesuai dengan hasil kerjanya.

8. Konseptual

Setiap pegawai bisa membuat konseptual dalam bekerja sehingga bisa meraih tujuan dengan baik 


\section{Kepemimpinan}

Jiwa kepemimpinan setiap pegawai harus dimiliki dengan adanya jiwa kepemimpinan maka pengembangan karir bisa diraih dengan mudah.

10. Balas jasa

Dengan pengembangan karir yang baik maka akann mendapat balsan yang baik juga

\section{Konsumen}

Konsumen sangatlah penting didalam dunia pekerjaan, maka dari itu konsumen harus lebih di pentingkan juga.

\section{Tahap Pengembangan karir}

Tahap pengembangan karir menurut Samsudin (dalam Sugiharjo \& Rustinah, 2017) adalah sebagai berikut:

1. Karir awal. Merupakan tahapan pertama dimana seseorang memasuki sebuah organisasi. Selama tahap masuk, karyawan memperoleh gambaran realistic mengenai organisasi, dan mencari pekerjaan yang paling sesuai dengan keahlian, pengalaman, preferensi dan minatnya.

2. Karir pertengahan. Merupakan suatu tahapan dimana setiap individu akan mengalami suatu transisi atau perubahan pada karirnya. Dalam tahap ini individu mengkaji ulang pencapaiannya sampai pada saat itu dan kemungkinan untuk mencapai karir pribadi dan tujuan hidup dimasa depan.

3. Karir akhir. Merupakan suatu titik balik terhadap produktivitas atau penurunan dan pension dini, dapat mengikuti suatu krisis pertengahan karir.

\section{Produktivitas Kerja}

Menurut Sedarmayanti (dalam Supendy \& Harsum, 2018) mengemukakan bahwa produktivitas adalah bagaimana menghasilkan atau meningkatkan hasil barang dan jasa setinggi mungkin dengan memanfaatkan sumber daya secara efisien. Oleh karena itu produktivitas sering diartikan sebagai rasio antara keluaran dan masukan salam satuan waktu tertentu.

Malayu S.P Hasibuan (dalam Hutabarat P, 2019) mengungkapkan bahwa secara lebih sederhana maksud produktivitas adalah perbandingan secara ilmu hidung antara jumlah yang dihasilkan dan jumlah setiap sumber yang dipergunakan selama produksi berlangsung. 
R Pebriyanti, F Mulia, R D M Danial/ Jimek vol 3 No 1 Tahun 2020

Konsep produktivitas pada dasarnya dilihat dari dua dimensi yaitu dimensi individu dan organisasi. Pengkajian produktivitas dari dimensi individu yaitu dalam hubungannya dengan karakteriktis kepribadian individu.

Menurut J Ravianto (dalam Hutabarat P, 2019) produktivitas kerja karyawan adalah perbandingan hasil yang dicapai dengan peranserta karyawan perusahaan per satuan waktu.

Menurut Henry Simamora (dalam Supendy \& Harsum, 2018) faktor-faktor yang dugunakan untuk mengukur produktivitas kerja adalah

1. Kuantitas kerja

Kuantitas adalah jumlah kerja yang dilaksanakan oleh seseorang pegawai dalam suatu periode tertentu.

2. Kualitas kerja

Mutu seorang karyawan dalam hal melaksanakan tugas-tugasnya meliputi pengetahuan, keterampilan dan kemampuan yang dimiliki.

3. Ketepatan waktu

Dimana tugas dapat diselesaikan atau hasil dapat dicapai dengan tepat waktu dan memaksimalkan waktu yang tersedia untuk menyelesaikan tugas yang lain.

\section{Faktor yang mempengaruhi Produktivitas kerja}

Menurut Sutrisno (dalam Manik, 2018) ada beberapa faktor yang mempengaruhi produktivitas kerja karyawan, yaitu:

1. Pelatihan

Latihan kerja dimaksudkan untuk melengkapi karyawan dengan keterampilan dan cara yang tepat untuk menggunakan peralatan kerja. Untuk itu, latihan kerja diperlukan bukan saja sebagai pelengkap akan tetapi sekaligus untuk memberikan dasar-dasar pengetahuan.

2. Mental dan kemampuan fisik karyawan

Keadaan mental dan fisik karyawan merupakan hal yang sangat penting untuk menjadi perhatian bagi organisasi sebab keadaan fisik dan mental mempunyai hubungan yang erat dengan produktivitas kerja karaywan.

3. Hubungan antara atasan dan bawahan 
R Pebriyanti, F Mulia, R D M Danial/ Jimek vol 3 No 1 Tahun 2020

Hubungan atasan dan bawahan akan mempengaruhi kegiatan yang dilaksanakan seharihari. Bagaimana pandangan atasan terhadap karyawan, sejauh mana karyawan diikutsertakan dalam penentuan tujuan.

\section{Hubungan pengembangan karir dengan produktivitas}

Rivai (dalam Juwita, 2016) produktivitas, pengalaman, pendidikan, dan kadang-kadang keberuntungan berpengaruh terhadap karir individu. Dengandemikian pengembangan karir merupakan tindakan seseorang pegawai untuk mencapai tujuan karirnya.

Pegawai harusnya diberikan kesempatan untuk meningkatkan kemampuannya seperti melalui pelatihan kursus dan juga melanjutkan jenjang pendidikan. Hal ini memberikan kesempatan pada pegawai untuk tumbuh dan berkembang sesuai yang dia inginkan.

Produktivitas adalah faktor paling penting dalam meningkatkan dan mengembangkan karir seorang pegawai karena kemajuan karir seseorang sebagian besar tergantung pada produktivitas yang baik.

\section{Hipotesis}

\section{H1 = Pengembangan Karir Berpengaruh Terhadap Produktivitas Kerja Karyawan.}

\section{METODE PENELITIAN}

Penelitian ini dilakukan di PT. Senamas Energindo Mineral, Jakarta. Metode penelitian yang digunakan adalah metode kuantitatif dengan analisis regresi liner sederhana. Metode penelitian kuantitatif merupakan salah satu jenis penelitian yang spesifikasinya adalah sistematis, terencana, dan terstrukstur dengan jelas sejak awal hingga pembuatan desain penelitiannya. Penelitian kuantitatif adalah penelitian yang banyak menuntut penggunaan angka, mulai dari pengumpulan data, penafsiran terhadap angka, serta penampilan dari hasilnya. Data kuantitatif yang digunakan dalam penelitian ini berasal dari kuesioner yang diberikan kepada karyawan PT. Senamas Energindo Mineral.

\section{Skala pengukuran}

Skala yang digunakan dalam penelitian ini adalah skala Likert. Skala likert adalah skala yang berisi tingkat jawaban yang merupakan skala sejenis ordinal. Skala ini mengukur ordinal karena hanya dapat membuat rangking tetapi tidak dapat diketahui beberapa kali satu responden lebih baik atau lebih buruk dari responden lainnya. 


\section{Tabel 1. Skala Likert}

\begin{tabular}{|l|l|l|}
\hline No & Pernyataan & Skala \\
\hline 1 & Sangat setuju (SS) & 5 \\
\hline 2 & Setuju (S) & 4 \\
\hline 3 & Ragu-ragu (RR) & 3 \\
\hline 4 & Tidak setuju (TS) & 2 \\
\hline 5 & Sangat tidak setuju (STS) & 1 \\
\hline
\end{tabular}

Sumber: Sugiyono, (2017)

\section{Populasi dan Sampel}

Populasi dalam penelitian ini adalah karyawan PT. Senamas Energindo Mineral. Sedangkan sampel yang digunakan dalam penelitian ini adalah teknik random sampling dengan jumlah 74 responden PT. Senamas Energindo Mineral.

\section{HASIL \& PEMBAHASAN}

\section{Uji Validitas}

Uji validitas digunakan untuk mengukur kevalidan suatu kuesioner penelitian. Suatu pertanyaan atau kuesioner dinyatakan valid jika $\mathrm{r}_{\text {hitung }}>\mathrm{r}_{\text {tabel. }}$. Maka item pertanyaan tersebut valid.

Tabel 2. Uji Validitas X dan Y

\begin{tabular}{|c|c|c|c|c|}
\hline Variabel X & $\begin{array}{l}\text { Nilai } \\
\text { hitung }\end{array}$ & R Nilai R tabel & $\begin{array}{l}\text { Nilai } \\
\text { signifikansi }\end{array}$ & Keputusan \\
\hline $\mathrm{X} 1.1$ & 0.387 & 0.227 & 0 & Valid \\
\hline $\mathrm{X} 1.2$ & 0.782 & 0.227 & 0 & Valid \\
\hline $\mathrm{X} 1.3$ & 0.670 & 0.227 & 0 & Valid \\
\hline
\end{tabular}


R Pebriyanti, F Mulia, R D M Danial/ Jimek vol 3 No 1 Tahun 2020

\begin{tabular}{lllll}
\hline Variabel Y & $\begin{array}{l}\text { Nilai } \\
\text { hitung }\end{array}$ & $\mathrm{R}$ Nilai R tabel & $\begin{array}{l}\text { Nilai } \\
\text { signifikansi }\end{array}$ & Keputusan \\
\hline Y1.1 & 0.674 & 0.227 & 0 & Valid \\
\hline Y1.2 & 0.720 & 0.227 & 0 & Valid \\
\hline Y1.3 & 0.720 & 0.227 & 0 & Valid
\end{tabular}

Sumber: hasil pengolahan data (2020)

Berdasarkan hasil diatas maka dapat disimpulan bahwa variabel pengembangan karir (X) dan produktivitas kerja (Y1) adalah valid karena keseluruhan $\mathbf{r}_{\text {hitung }}$ lebih besar dari pada $\mathbf{r}_{\text {tabel. }}$

\section{Uji Reliabilitas}

Jika koefisien realiabilitas (Alpha) mendekati 1 berarti sangat baik, jika berada di atas 0,7 baik, tetapi bila berada di bawah 0.6 berarti tidak baik. Maka apabila nilai Alpha berada di bawah 0,6 , maka pengukuran yang dilakukan tidak reliabel.

\section{Tabel 3. Hasil Uji Reliabilitas X1}

\section{Reliability Statistics}

Cronbach's

\begin{tabular}{l|l} 
Alpha & N of Items \\
\hline .234 & 3
\end{tabular}

Sumber: hasil pengolahan data (2020)

Berdasarkan hasil uji reliabilitas pada variabel $X$ yaitu pengembangan karir menghasilkan 0.234 lebih besar dari 0.6 maka kuesioner variabel X menunjukan Reliabel.

\section{Tabel 4. Hasil Uji Reliabilitas Y}

\section{Reliability Statistics}

\begin{tabular}{l|l}
$\begin{array}{l}\text { Cronbach's } \\
\text { Alpha }\end{array}$ & N of Items \\
\hline .486 & 3
\end{tabular}

Sumber: hasil pengolahan data (2020) 
R Pebriyanti, F Mulia, R D M Danial/ Jimek vol 3 No 1 Tahun 2020

Berdasarkan hasil uji reliabilitas pada variabel Y yaitu produktivitas kerja menghasilkan 0.486 lebih besar dari 0.6 maka kuesioner variable Y menunjukan Reliabel.

\section{Analisis Regresi Linier Sederhana}

Tabel 5. Analisis Regresi Linier Sederhana

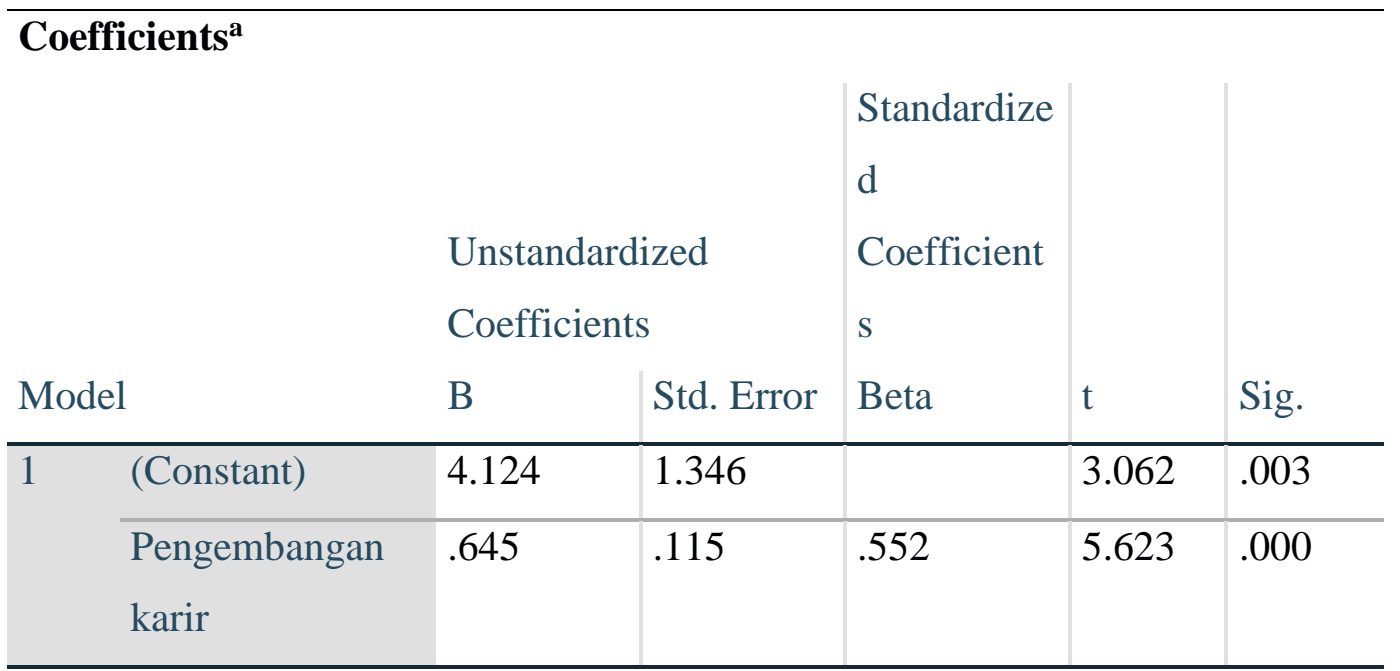

a. Dependent Variable: produktivitas kerja

Sumber: hasil pengolahan data (2020)

Berdasarkan hasil kuesioner yang diolah dengan menggunakan SPSS, maka dapat dihasilkan analisis regresi linier sederhanan sebagai berikut :

$\mathrm{Y}=\mathrm{a}+\mathrm{bx}$

$\mathrm{Y}=4.124+0.645 \mathrm{X}$

Maka persamaan tersebut bisa disimpulkan sebagai berikut:

1. Konstanta sebesar 4.124, mengandung arti bahwa koefisien variabel produktivitas kerja adalah sebesar 4.124 .

2. Koefisien regresi $X$ sebesar 0.645 menyatakan bahwa setiap penambahan $1 \%$ nilai pengembangan karir, maka nilai produktivitas kerja bertambah sebesar 0.645. koefisien regresi tersebut bernilai positif, sehingga dapat dikatakan bahwa arah pengaruh variabel $\mathrm{X}$ terhadap Y adalah positif. 


\section{Uji T (Parsial)}

Tabel 6. Hasil Uji T

Coefficients $^{\mathrm{a}}$

\begin{tabular}{|c|c|c|c|c|c|c|}
\hline & & \multicolumn{2}{|c|}{$\begin{array}{l}\text { Unstandardized } \\
\text { Coefficients }\end{array}$} & \multirow[t]{2}{*}{$\begin{array}{l}\text { Standardize } \\
\text { d } \\
\text { Coefficient } \\
\text { s } \\
\text { Beta }\end{array}$} & \multirow[b]{2}{*}{$\mathrm{t}$} & \multirow[b]{2}{*}{ Sig. } \\
\hline \multicolumn{2}{|c|}{ Model } & B & Std. Error & & & \\
\hline \multirow[t]{2}{*}{1} & (Constant) & 4.124 & 1.346 & & 3.062 & .003 \\
\hline & $\begin{array}{l}\text { Pengembangan } \\
\text { karir }\end{array}$ & .645 & .115 & .552 & 5.623 & .000 \\
\hline
\end{tabular}

a. Dependent Variable: produktivitas kerja

Sumber: hasil pengolahan data (2020)

\section{$H_{1}=$ Kualitas pengembangan karir terhadap produktivitas kerja}

1. Berdasarkan data diatas dapat dilihat signifikan pengembangan karir (X) $0.000<0.05$ maka terdapat hubungan antara pengembangan karir $(\mathrm{X})$ terhadap produktivitas kerja $(\mathrm{Y})$.

2. Berdasarkan nilai $\mathrm{t}$ hitung sebesar $5.623>\mathrm{t}$ tabel 1.996, sehingga dapat disimpulkan bahwa pengembangan karir $(X)$ berpengaruh terhadap variabel produktivitas kerja. $r_{\text {tabel }}=(a / 2$; $\mathrm{n}-\mathrm{k}-1)=(0.05 / 2 ; 74-1-1)=(0.025 ; 72)=1.996$

\section{Uji F (Simultan)}

Tabel 7. Hasil Uji F

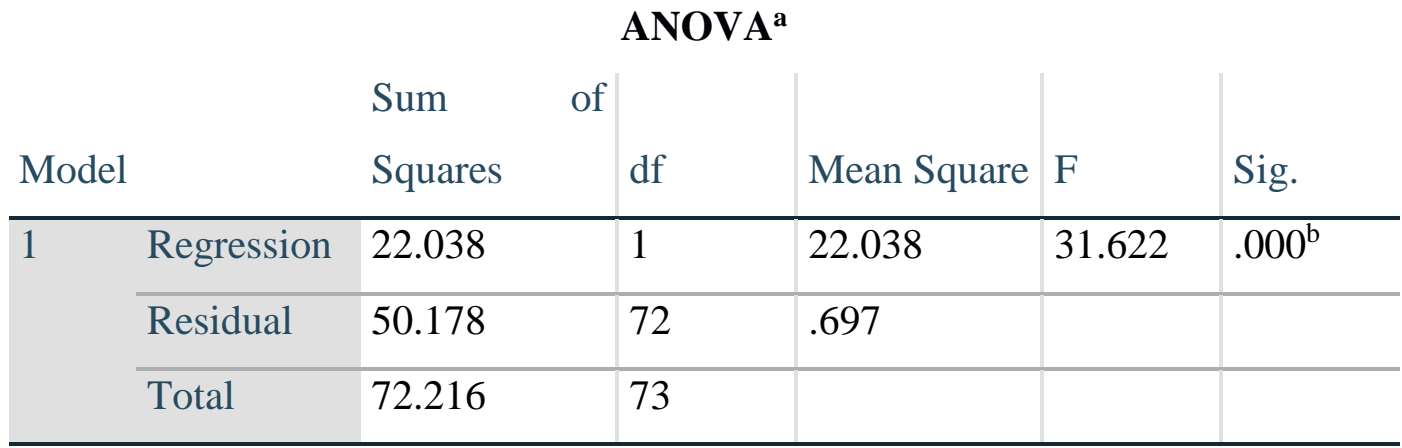

a. Dependent Variable: produktivitas kerja

b. Predictors: (Constant), Pengembangan karir

Sumber: hasil pengolahan data (2020)

1. Berdasarkan data diatas dapat dilihat signifikan sebesar $0.000<0.05$ maka terdapat hubungan antara pengembangan karir $(\mathrm{X})$ terhadap produktivitas kerja $(\mathrm{Y})$. 
R Pebriyanti, F Mulia, R D M Danial/ Jimek vol 3 No 1 Tahun 2020

2. Berdasarkan $\mathrm{F}_{\text {tabel }}=\mathrm{F}(\mathrm{k} ; \mathrm{n}-\mathrm{k})=\mathrm{F}(1 ; 74-1)=\mathrm{F}(1 ; 73)=3.97$. Berarti $\mathrm{F}_{\text {hitung }} 31.622>3.97$, sehingga terdapat pengaruh secara simultan antara pengembangan karir terhadap produktivitas kerja.

\section{SIMPULAN \& SARAN}

Dari pembahasan diatas dapat disimpulkan bahwa pengembangan karir berpengaruh terhadap produktivitas kerja. Maka peneliti menyarankan kepada pihak PT. Senamas Energindo Mineral untuk meningkatkan efektivitas pengembangan karir agar pegawai merasa terdorong dan termotivasi sehingga dapat mencapai produktivitas yang maksimal hal itu juga dalam meningkatkan keuntungan bagi perusahaan tersebut.

\section{DAFTAR PUSTAKA}

Abdullah, D. (2016). Pengaruh Pengembangan Karir Dan Kepuasan Kerja Terhadap Produktivitas Kerja Karyawan Pt. Gistex Garment Indonesia Kabupaten Majalengka. MAKSI Jurnal Ilmiah Manajemen \& Akuntansi, 3(2), 2356-3923.

Fauzi, F., \& Siregar, M. H. (2015). Pengaruh Kompetensi dan Kinerja Karyawan terhadap Pengembangan Karir di Perusahaan Konstruksi. Journal of Entrepreneurship, Management, and Industry (JEMI), 9(1), 121-126.

Hutabarat P, Y. (2019). Pengaruh Performance, Orientasi dan Pengembangan Karir terhadap Produktivitas Kerja pada PT.DGS Surya Mas Indonesia Cabang Medan. 1(1).

Juwita. (2016). Artikel ilmiah pengaruh pengembangan karier terhadap produktivitas pegawai rumah sakit umum daerah rokan hulu.

Litano, M. L., \& Major, D. A. (2016). Facilitating a Whole-Life Approach to Career Development: The Role of Organizational Leadership Facilitating a Whole-Life Development : The Role of. Psychology Faculty Publications, 43, 52-65.

Manik, S. (2018). Faktor-faktor yang mempengaruhi Produktivitas Kerja Baryawan pada bank Danamon Simpan Pinjam. 3.

Massie, R., Tewal, B., \& Sendow, G. (2015). Pengaruh Perencanaan Karir, Pelatihan Dan Pengembangan Karir Terhadap Kinerja Pegawai Pada Museum Negeri Provinsi Sulawesi Utara. Jurnal Berkala Ilmiah Efisiensi, 15(05), 635-645.

Sugiharjo, R. J., \& Rustinah. (2017). Pengaruh Perencanaan Karir, Pengembangan Karir Karyawan, dan Kompensasi terhadap Kinerja Karyawan pada Jambuluwuk Puncak Resort. III(03), 444-454. 
R Pebriyanti, F Mulia, R D M Danial/ Jimek vol 3 No 1 Tahun 2020

Supendy, R., \& Harsum. (2018). Pengatuh Pengembangan Karir Terhadap Produktivitas Karyawan PT. POS Indonesia (Persero) Kendari. 7. 